Research Article

\title{
Dynamic Analysis of Pantograph-Catenary System considering Ice Coating
}

\author{
Yongming Yao $\mathbb{D}^{1,2}$ Ning Zhou ${ }^{1}{ }^{1}{ }^{1}$ Guiming Mei, ${ }^{1}$ and Weihua Zhang ${ }^{1}$ \\ ${ }^{1}$ State Key Laboratory of Traction Power, Southwest Jiaotong University, No. 111, First Section, North of Second Ring Road, \\ Chengdu, Sichuan, 610031, China \\ ${ }^{2}$ Institute of Railway Technology (IRT), Department of Mechanical \& Aerospace Engineering, Monash University, \\ 195 Wellington Road, Clayton, Melbourne, VIC 3800, Australia
}

Correspondence should be addressed to Ning Zhou; zhou_ningbb@sina.com

Received 6 April 2020; Revised 17 August 2020; Accepted 26 August 2020; Published 7 September 2020

Academic Editor: N. A. Saeed

Copyright ( 2020 Yongming Yao et al. This is an open access article distributed under the Creative Commons Attribution License, which permits unrestricted use, distribution, and reproduction in any medium, provided the original work is properly cited.

\begin{abstract}
Ice coating on overhead contact system (OCS) will affect the sliding of pantograph, and arc discharge phenomena will occur between pantograph and catenary, which will threaten the normal operation of train. This paper presents a comprehensive model to analyze the dynamics of icing on pantograph-catenary (PAC) system. The finite element model (FEM) is used for building the catenary, the pantograph is modeled as lumped-mass model, and the ice section of the cable is fan-shaped. The increased density method, uniform load method, and combinatorial material method of icing are used to analyze the icing problem of PAC system. The similarities and differences between the three simulation methods are compared. The influence of the ice thickness on the current collection quality between the pantograph and catenary at the different operating speeds calculated by the three methods is basically the same, which fully illustrates the effectiveness of the simulated ice coating method. In comparison, the combinatorial material method is a more reasonable method for calculating the icing of catenary systems. The research also shows that the influence of icing on the current collection quality of PAC system is different when the train runs at different speeds. Specifically, as the speed of trains increases, the effect of ice thickness on the current collection quality of the PAC system is becoming increasingly apparent.
\end{abstract}

\section{Introduction}

The overhead contact system (OCS) is an important part of electrified railway, which provides electric energy for train traction. Whether the contact between pantograph and catenary system is good directly affects the current collection quality of locomotive [1]. Good current collection quality is the premise of reliability, stability, and safety of railway transportation. The OCS is laid along the train's running line which is vulnerable to the environment such as crosswind, rain, and snow. With the wider distribution of rail transit lines, the icing problem of catenary is becoming increasingly prominent. The icing phenomenon often happens in pantograph-catenary system in winter, especially under the conditions of low temperature and humidity [2].
Ice-coating of transmitted wire is an ongoing problem of PAC system and has gained a great interest in recent years [3]. For the OCS, the tension of contact wire and messenger wire will change after icing, and the sag and initial position of OCS will change at the same time [4]. In addition, icing will introduce irregularity on the contact wire surface, such as wear and geometric deformation, which will affect the pantograph sliding along the catenary [5-7]. It will also cause arcing between the contact wire and the contact piece and burn the carbon slide plate. Therefore, icing affects the current collection quality of the PAC system, damages the equipment, and threatens the safe operation of the train [8-11]. Mechanism of icing [12], modeling of ice accretion on wires [13], galloping of iced conductors [14], and the influences of icing on current collection [15] have been 
investigated and discussed in detail by the scholars, through experiments and simulations.

At present, the icing mechanism of transmission lines is mainly studied from the perspectives of meteorology, fluid mechanics, and thermodynamics [16, 17]. From a fluid mechanics perspective, icing on transmission lines is a physical phenomenon that occurs when trapped over-cooled water droplets in the airflow [18, 19]. From a thermodynamic point of view, ice coating is a physical process in which liquid supercooled water droplets release energy and solidify [20]. Icing is a comprehensive physical phenomenon that is mainly determined by meteorological conditions such as ambient temperature, humidity, convection of warm and cold air, wind speed, and wind direction.

The phenomenon of icing is accidental, uncertain, and affected by complex climatic and geographic factors, which restricts the study of icing models. Conductor icing is affected by factors such as temperature, humidity, convection of warm and cold air, circulation, and wind. The research on the icing model mainly focuses on the prediction of the icing growth and icing shape. There are about 20 traditional prediction models of conductor icing, including the Lenhard model [21], the Chaine and Skeates model [22, 23], the Imaim model [24], the Makkonen model [25], the Goodwin model [26], Chaine and Castonquay model [27], simple model of glaze icing [28], McComber and Govoni model [29]. The ice-covering model of intelligent algorithm is based on the local mass balance and heat balance as the basis for ice-covering growth. The aerodynamic equation is used to solve the parameters of airflow field around the icing wire and the convection heat transfer coefficient of the icing surface [30]. Among them, the calculation of the droplet flow field mainly includes the Euler method [31] and the Lagrangian method $[32,33]$. Spalart-Allmaras model and $k-\varepsilon$ model are used to calculate the atmospheric flow field of iced conductor. In summary, most of the classic ice-coating models are based on mathematical empirical formulas and statistical results. These models only consider changes in parameters such as temperature, wind speed, and content of liquid water [34], and often ignore overflow water, load current, wire temperature, and other factors. The ice-covering model based on the intelligent algorithm considers more factors that affect icing, which is better to predict the growth of ice coating. And it can accurately predict the icing morphology, which has a greater advantage in simulating of icing.

Icing will not only severely affect the quality of the current collection, but also cause a large amplitude oscillation of the catenary under the crosswind, which is also called galloping $[35,36]$. Icing will affect the aerodynamic stability of OCS, which may cause huge-amplitude vibration [37-39]. The aerodynamic forces will greatly affect the initial equilibrium position, which will result in different critical wind speeds and galloping amplitudes of an iced transmission line [40]. The icing of the catenary system has a great influence on the relevant aerodynamic parameters. Increasing of icing thicknesses increases wind deviations of contact wires and changes the wind vibration mode of contact wires, which will damage the catenary system of high-speed railways [41, 42]. A series of wind tunnel tests of iced contact wires were conducted to study the galloping of iced conductor, which proves that the increase of icing thickness will reduce the aerodynamic stability of contact wire [43].

Icing will change the static characteristics of the catenary system. As the thickness of the ice increases, the sags of the contact wire and the messenger wire and the displacement at the end anchorage will increase [44]. When the train passes through the ice-covered catenary system, the interaction between the pantograph and the catenary will change [45]. As the thickness of the ice increases, the contact performance between the contact piece and the contact wire will deteriorate, thereby reducing the current collection quality between pantograph and catenary.

The existing research results mainly focus on the influence of icing shape and thickness on the static characteristics of OCS. However, the research on the current collection performance of the OCS after icing is not enough. This paper presents a method based on the finite element method to analyze the dynamics of icing on PAC system, in which the catenary is a finite element model and the pantograph is a lumped-mass model. The increased density method, uniform load method, and combinatorial material method of icing are used to analyze the icing problem of PAC system.

The paper is organized as follows. In this paper, a dynamic model of pantograph and catenary considering icing is proposed. In this model, the key parts such as messenger wire, contact wire, auxiliary messenger wire, and dropper are all considered to be covered with ice. Section 2 introduces the modeling of PAC coupling system and validates the PAC dynamic model according to EN50318:2018. In Section 3, three different methods are put forward to solve the ice covering of catenary system, which are increased density method, uniform load method, and combinatorial material method. Based on the three different models proposed in this paper, the icing problems of catenary system under different operating speeds are simulated and analyzed in Section 4. Finally, by comparing the simulation results of the three models, the conclusion that the icing of catenary affects the current collection quality of pantograph catenary system is given. Finally, concluding remarks are given in Section 5.

\section{Pantograph-Catenary Coupling Dynamics Model}

The Moscow-Kazan high-speed railway that runs from the Russian capital, Moscow, extends to Kazan in the Tatar Republic to the southeast. The total length of the line is about 770 kilometers, and the design speed is up to $400 \mathrm{~km} / \mathrm{h}$. The line is located in high latitudes and cold regions, with extreme winter temperatures as low as $-55^{\circ} \mathrm{C}$. Seasonal frozen soil and soft soil are widely distributed along the line, and the ice thickness in some areas reaches $15 \mathrm{~mm}$. The MoscowKazan high-speed railway project faces complex, harsh, and high-speed target requirements. 
2.1. Catenary Model. The overhead contact system is installed considering a sequence of spans, where each series comprises an independent system. The catenary system of Moscow-Kazan high speed railway adopts stitched catenary. The stitched catenary system is mainly composed of contact wire, messenger wire, auxiliary messenger wire, dropper, and support positioning devices, as depicted in Figure 1. The catenary is a continuous system that can be modeled using the Finite Element Method (FEM) techniques [46]. The contact wire, messenger wire and auxiliary messenger wire are built up from beam elements, and the droppers are modeled as link element. The finite element code ANSYS was adopted for the dynamic analysis of the catenary system. The contact algorithm between contact wire and contact piece adopts the augmented Lagrange multiplier method. For the initial state of the catenary, the splitting method based on the idea of model splitting is used to split the OCS into two parts, the messenger wire and the contact wire [47].

The length of the span is $50 \mathrm{~m}$ and the structure height of catenary is $1.6 \mathrm{~m}$. There are six droppers in a single span, and the distance of the dropper in a single span is $5,8,8,8,8$, and $5 \mathrm{~m}$, respectively. The material parameters of catenary are shown in Table 1.

A Lagrange equation of the second kind is used to establish the differential equation of motion of the catenary. First, the kinetic energy and potential energy of the whole system are calculated.

The total kinetic energy of the system is the kinetic energy of all mass movements, including messenger wire, contact wire, auxiliary messenger wire, dropper, support rod, and limiter. The total kinetic energy can be expressed as the following:

$$
T=T_{M}+T_{C}+T_{A}+T_{D}+T_{R}+T_{L},
$$

where $T_{M}, T_{C}, T_{A}, T_{D}, T_{R}, T_{L}$ are the kinetic energy of the messenger wire, contact wire, auxiliary messenger wire, dropper, support rod, and limiter, respectively.

The potential energy of the system includes the potential energy of elastic deformation and the potential energy of all tensions. The total potential energy can be written as

$$
V=V_{T}+V_{B}+V_{D}+V_{R}
$$

where $V_{T}$ is the potential energy of all tensions; $V_{B}$ is the potential energy of bending; $V_{D}, V_{R}$ are the elastic deformation of dropper and support rod, respectively.

Therefore, according to Lagrange's equation, the total energy of the system can be expressed as the following

$$
\begin{aligned}
\Gamma & =T-V, \\
\frac{\mathrm{d}}{\mathrm{d} t}\left(\frac{\partial \Gamma}{\partial q_{i}}\right)-\frac{\partial \Gamma}{\partial q_{i}} & =Q_{i},
\end{aligned}
$$

where, $q_{i}$ is the generalized coordinate and $Q_{i}$ is the generalized force. By substituting the expressions of total kinetic energy and total potential energy, the differential equation of catenary motion can be obtained:

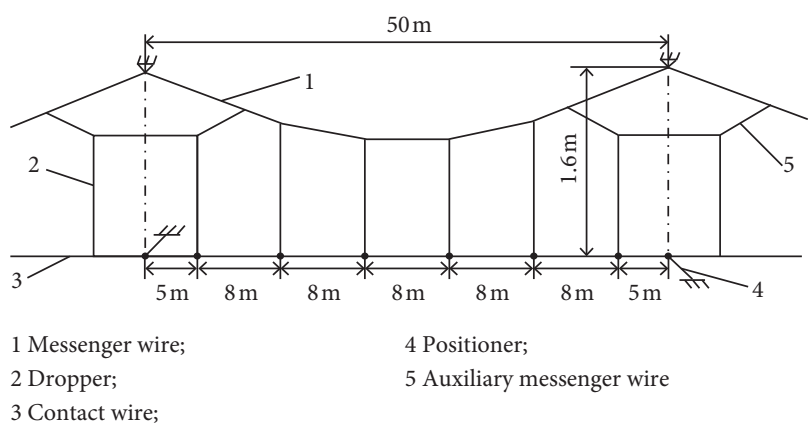

Figure 1: The stitched catenary system. 1. Messenger wire. 2. Dropper. 3. Contact wire. 4. Positioner. 5. Auxilary messenger wire.

$$
[M]\{\ddot{q}\}+[K]\{q\}=0,
$$

where $M$ is the mass matrix, and $K$ is the stiffness matrix.

2.2. Pantograph Model. The DSA380-type pantograph is built. Its lower arm is connected to the base frame. One end of the upper arm is connected with the lower arm, and the other end is connected with the collector piece. The contact pieces are installed on the top of the pantograph which connects the collector piece with spring. Figure 2 shows the structure of a DSA380 pantograph system.

The pantograph was modeled as a lumped-mass model in accordance with a model of DSA380, detailed in Table 2. In all the cases discussed in the paper, the uplift force follows the equation $0.00097 v^{2}+70 \mathrm{~N}$, where $v$ is the running speed of the vehicle.

2.3. Pantograph-Catenary Interaction Validation. EN50318:2018 [48] specifies the validation requirements of a PAC interaction computational model. According to en50318:2018, the model of AC stitched catenary and double pantograph with distance of $200 \mathrm{~m}$ is established. The operation speed of pantograph is $275 \mathrm{~km} / \mathrm{h}$ and $320 \mathrm{~km} / \mathrm{h}$, respectively. The coupled model of PAC is established according to the parameters that are given in EN50318:2018. The results of contact force are shown in Figure 3.

Table 3 shows the obtained values over the reference model previously described. Compared with the stipulations European Standard EN50318:2018, the values of the simulations are within the specified range. Thus, the performance of the model is satisfactory to carry out simulations of the PAC interaction with enough accuracy.

\section{The Ice-Coating Model}

Crescent-shaped, D-shaped, and fan-shaped icing are the three most common icing shapes for catenary systems. This article considers that the ice-covering shapes of the messenger wire, auxiliary messenger wire, contact wire, and dropper are all fan-shaped. The ice-covering section is shown in Figure 4. It is assumed that the ratio of the ice thickness $d$ of the messenger wire, auxiliary messenger wire, 
TABLE 1: Parameters of catenary.

\begin{tabular}{lccccc}
\hline Component & Tension $(\mathrm{kN})$ & Line density $(\mathrm{kg} / \mathrm{m})$ & Modulus of elasticity $(\mathrm{Pa})$ & Poisson's ratio & ${\text { Cross section area }\left(\mathrm{mm}^{2}\right)}^{2}$ \\
\hline Messenger wire & 28 & 1.095 & $1.05 \mathrm{E}+11$ & 0.35 & 150 \\
Contact wire & 36 & 1.345 & $1.1 \mathrm{E}+11$ & 0.34 & 120 \\
Auxiliary messenger wire & 3.5 & 0.331 & $1.05 \mathrm{E}+11$ & 0.31 & 35 \\
Dropper & - & 0.09 & $1.2 \mathrm{E}+11$ & 0.35 & 10 \\
\hline
\end{tabular}

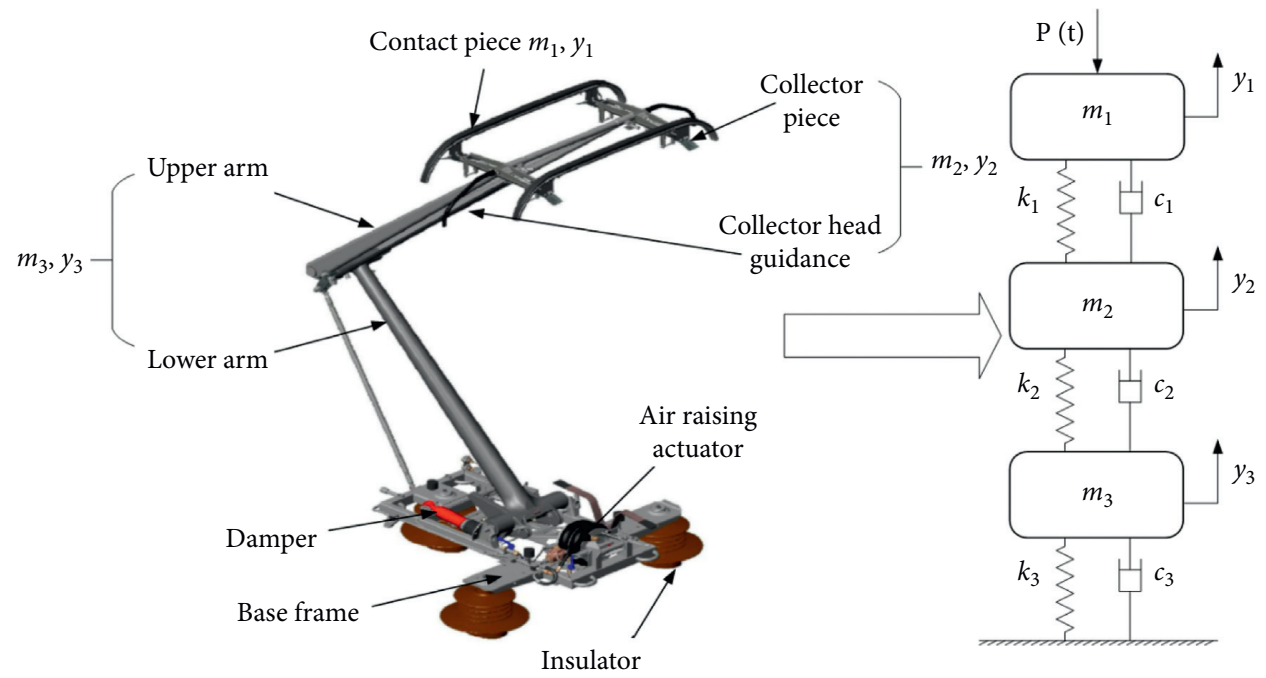

FIGURe 2: Dynamic modeling of the pantograph.

TABle 2: Parameters of the pantograph.

\begin{tabular}{lcc}
\hline Parameter & Symbol & Value \\
\hline Mass of contact piece & $\mathrm{m}_{1}$ & $7.12 \mathrm{~kg}$ \\
Mass of collector piece & $\mathrm{m}_{2}$ & $6 \mathrm{~kg}$ \\
Mass of frame & $\mathrm{m}_{3}$ & $5.8 \mathrm{~kg}$ \\
Stiffness of contact piece & $\mathrm{k}_{1}$ & $9430 \mathrm{~N} / \mathrm{m}$ \\
Stiffness of collector piece & $\mathrm{k}_{2}$ & $14100 \mathrm{~N} / \mathrm{m}$ \\
Stiffness of frame & $\mathrm{k}_{3}$ & $0.1 \mathrm{~N} / \mathrm{m}$ \\
Damping of contact piece & $\mathrm{c}_{1}$ & $0 \mathrm{~N} /(\mathrm{m} / \mathrm{s})$ \\
Damping of collector piece & $\mathrm{c}_{2}$ & $0 \mathrm{~N} /(\mathrm{m} / \mathrm{s})$ \\
Damping of frame & $\mathrm{c}_{3}$ & $70 \mathrm{~N} /(\mathrm{m} / \mathrm{s})$ \\
\hline
\end{tabular}

contact wire, and dropper to the respective radius $r$ is the same, all being $\lambda$.

$$
\lambda=\frac{d}{r}
$$

3.1. Increased Density Method. The method of increasing density is to treat the icing as an increase in the density of the cable, and the mass of the icing is equivalent to the mass of the cable. The change in the shape of the cable after icing was not considered, and the inertial effect caused by icing was considered. The density of the iced cable can be written as

$$
\rho^{\prime}=\frac{\theta}{2 \pi}\left(\lambda^{2}+2 \lambda\right) \rho_{\text {ice }}+\rho_{\text {wire }},
$$

where, $\rho_{\text {ice }}$ is the density of ice and $\rho_{\text {wire }}$ is the density of cable (messenger wire, auxiliary messenger wire, contact wire, and dropper).

When the density increases, the mass of the catenary increases and the kinetic energy changes. The kinetic energy expression of catenary is as follows:

$$
\begin{aligned}
T= & \frac{1}{2} \int_{0}^{L} \rho_{M}^{\prime} S_{M}\left(\frac{\partial z_{M}}{\partial t}\right)^{2} \mathrm{~d} x+\frac{1}{2} \int_{0}^{L} \rho_{C}^{\prime} S_{C}\left(\frac{\partial z_{C}}{\partial t}\right)^{2} \mathrm{~d} x \\
& +\frac{1}{2} \int_{0}^{l} \rho_{A}^{\prime} S_{A}\left(\frac{\partial z_{A}}{\partial t}\right)^{2} \mathrm{~d} x \\
& +\sum_{j=1}^{N_{T}} \frac{1}{2} m_{R_{j}}\left(\frac{\partial z_{M}}{\partial t}\right)^{2}+\sum_{j=1}^{N_{T}} \frac{1}{2} m_{L_{j}}\left(\frac{\partial z_{C}}{\partial t}\right)^{2} \\
& +\sum_{j=1}^{N_{T}} \frac{1}{2} m_{D j}^{\prime}\left(\frac{\partial z_{M}}{\partial t}-\frac{\partial z_{C}}{\partial t}\right)^{2},
\end{aligned}
$$

where $\rho_{M}^{\prime}, \rho_{C}^{\prime}, \rho_{A}^{\prime}$ are the density of messenger wire, contact wire, and auxiliary messenger wire after icing, respectively; $S_{M}, S_{C}, S_{A}$ are the cross-sectional area of messenger wire, contact wire, and auxiliary messenger wire, respectively; $m_{R_{j}}$ and $m_{L_{j}}$ are the mass of $j$-th support rod and limiter, respectively; $m_{D j}^{\prime}$ is the mass of $j$-th dropper after icing.

The strain energy of catenary can be expressed as follows: 


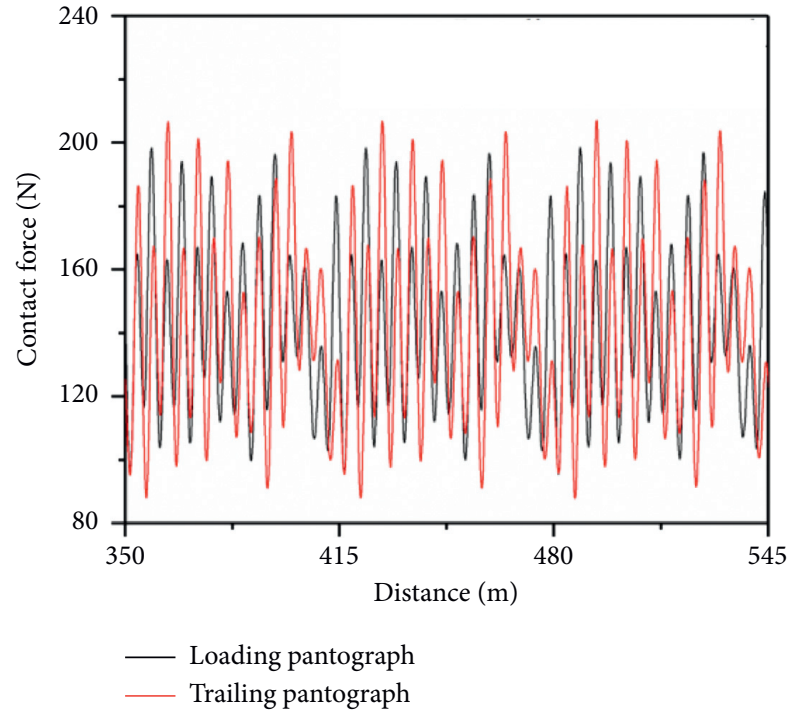

(a)

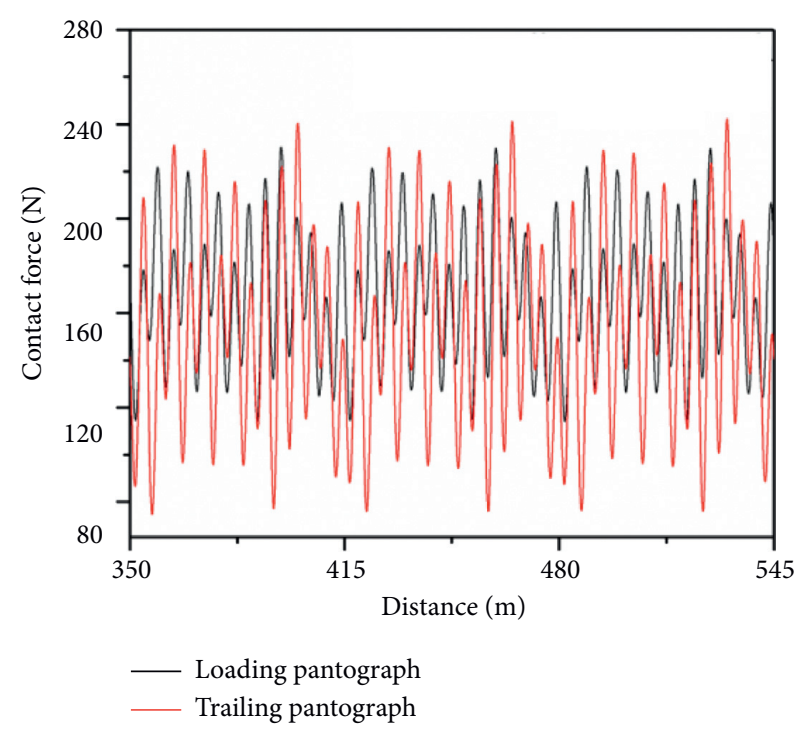

(b)

FIgURE 3: Contact force of reference model in EN50318-2018:(a) $275 \mathrm{~km} / \mathrm{h}$ (b) $320 \mathrm{~km} / \mathrm{h}$.

TABLE 3: Validation of the PAC model from reference model of EN50318-2018.

\begin{tabular}{|c|c|c|c|c|}
\hline \multicolumn{5}{|c|}{ Simulation results } \\
\hline Speed $(\mathrm{km} / \mathrm{h})$ & \multicolumn{2}{|c|}{275} & \multicolumn{2}{|c|}{320} \\
\hline Pantograph & Leading-pantograph & Trailing-pantograph & Leading-pantograph & Trailing-pantograph \\
\hline Pantograph distance $(\mathrm{m})$ & \multicolumn{2}{|c|}{200} & \multicolumn{2}{|c|}{200} \\
\hline$F_{\mathrm{m}}(\mathrm{N})$ & 143.11 & 142.09 & \multicolumn{2}{|c|}{169} \\
\hline$\sigma(\mathrm{N})$ & 24.1 & 28.85 & 23.78 & 37.89 \\
\hline Actual maximum of contact force $(\mathrm{N})$ & 198.52 & 207.12 & 230.28 & 242.45 \\
\hline Actual minimum of contact force $(\mathrm{N})$ & 95.43 & 87.88 & 113.94 & 74.85 \\
\hline Percentage of loss of contact (\%) & 0 & 0 & 0 & 0 \\
\hline
\end{tabular}

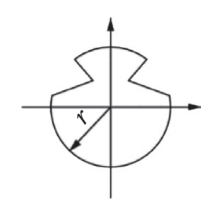

(a)

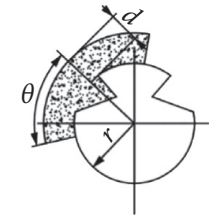

(b)

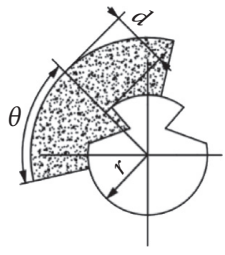

(c)

Figure 4: Cross section diagram of cables with different icing thickness. (a) $d=0$ (No Ice). (b) $d=r / 2$. (c) $d=r$.

$$
\begin{aligned}
V= & \frac{1}{2} \int_{0}^{L}\left(E_{M} I_{M}\left(\frac{\partial^{2} z_{M}}{\partial t^{2}}\right)^{2}+T_{M}\left(\frac{\partial z_{M}}{\partial t}\right)^{2}\right) \mathrm{d} t+\frac{1}{2} \int_{0}^{L}\left(E_{C} I_{C}\left(\frac{\partial^{2} z_{C}}{\partial t^{2}}\right)^{2}+T_{C}\left(\frac{\partial z_{C}}{\partial t}\right)^{2}\right) \mathrm{d} t \\
& +\frac{1}{2} \int_{0}^{l}\left(E_{A} I_{A}\left(\frac{\partial^{2} z_{A}}{\partial t^{2}}\right)^{2}+T_{A}\left(\frac{\partial z_{A}}{\partial t}\right)^{2}\right) \mathrm{d} t+\frac{1}{2} \sum_{j=1}^{N_{T}} k_{R_{j}} z_{M}^{2}+\frac{1}{2} \sum_{j=1}^{N_{T}} k_{L_{j}} z_{C}^{2}+\frac{1}{2} \sum_{j=1}^{N_{D}} k_{D_{j}}\left(z_{M}-z_{C}\right)^{2},
\end{aligned}
$$

where $E_{M}, E_{C}, E_{A}$ are the elastic modulus of messenger wire, contact wire, and auxiliary messenger wire respectively;
$I_{M}, I_{C}, I_{A}$ are the moment of inertia of messenger wire, contact wire, and auxiliary messenger wire, respectively; 
$T_{M}, T_{C}, T_{A}$ are the tension of messenger wire, contact wire, and auxiliary messenger wire, respectively; $k_{R_{j}}, k_{L_{j}}, k_{D_{j}}$ are the stiffness of $j$-th support rod, limiter, respectively.

3.2. Uniform Load Method. The uniform load method applies ice as a load on the catenary system (as shown in Figure 5), regardless of the shape and inertia of the ice. Here, the tension of catenary does not change with the application of uniform load.

Let the ice-covering force vector on any microsegment of the catenary be $\mathbf{F}(x, t)$ and the microend displacement vector be $\mathbf{r}_{c}$, then the expression of the virtual work generated by the ice-covering on the catenary can be expressed as

$$
\delta W=\int_{0}^{l} \delta \mathbf{r}_{Z}^{T} \mathbf{F}(x, t) \mathrm{d} x=\delta \mathbf{q}^{T} \int_{0}^{l} \delta \mathbf{B}_{Z}^{T} \mathbf{F}(x, t) \mathrm{d} x=\delta \mathbf{q}^{T} \mathbf{Q} .
$$

The generalized force generated by ice coating can be obtained as

$$
\mathbf{Q}=\int_{0}^{l} \delta \mathbf{B}_{Z}^{T} \mathbf{F}(x, t) \mathrm{d} x .
$$

The dynamic equation of iced catenary model is proposed as

$$
\mathbf{M} \ddot{q}+\mathbf{C} \dot{q}+\mathbf{K q}=\mathbf{Q}_{\mathbf{P}}+\mathbf{Q},
$$

where $\mathbf{M}$ is the mass matrix of the iced catenary system, $\mathrm{K}$ is the stiffness matrix of the iced catenary system, $\mathbf{C}$ is the constraint equation of the iced catenary system, and $\mathbf{Q}_{\mathbf{p}}$ is the generalized force vector of contact force relative to generalized coordinate.

3.3. Combinatorial Material Method. The catenary system changes the shape of the cable and its inertial characteristics at the same time. The coupling system of cable and ice will participate in the vibration of the catenary system with a new material property. The material properties of the new material are determined by the properties of the cable and ice together and are affected by the respective proportions of the two materials. The properties of the new material can be calculated from equation (12)

$$
\left\{\begin{array}{l}
E I=E_{\text {wire }} I_{\text {wire }}+E_{\text {ice }} I_{\text {ice }} \\
E A=E_{\text {wire }} A_{\text {wire }}+E_{\text {ice }} A_{\text {ice }}, \\
G A=G_{\text {wire }} A_{\text {wire }}+G_{\text {ice }} A_{\text {ice }}
\end{array}\right.
$$

where $E, A, I, G$ are the elastic modulus, cross-sectional area, the moment of inertia, and modulus of rigidity of the cable with no ice; $E_{\text {wire }}, A_{\text {wire }}, I_{\text {wire }}, G_{\text {wire }}$ are the elastic modulus, cross-sectional area, the moment of inertia and modulus of rigidity of the cable after icing; $E_{\text {ice }}, A_{\text {ice }}, I_{\text {ice }}, G_{\text {ice }}$ are the elastic modulus, cross-sectional area, the moment of inertia, and modulus of rigidity of ice.

Catenary icing results in parameter changes and the kinetic and strain energy of the catenary changes

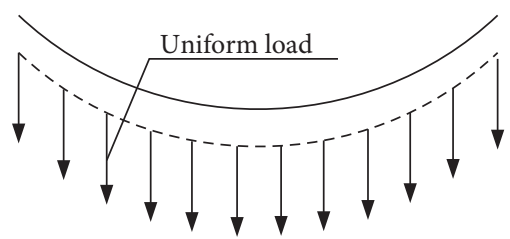

Figure 5: Uniform load on cable.

accordingly. The kinetic energy of the catenary after the parameter change can be expressed as

$$
\begin{aligned}
T= & \frac{1}{2} \int_{0}^{L} \rho_{M}^{\prime} S_{M}^{\prime}\left(\frac{\partial z_{M}}{\partial t}\right)^{2} \mathrm{~d} x+\frac{1}{2} \int_{0}^{L} \rho_{C}^{\prime} S_{C}^{\prime}\left(\frac{\partial z_{C}}{\partial t}\right)^{2} \mathrm{~d} x \\
& +\frac{1}{2} \int_{0}^{l} \rho_{A}^{\prime} S_{A}^{\prime}\left(\frac{\partial z_{A}}{\partial t}\right)^{2} \mathrm{~d} x \\
& +\sum_{j=1}^{N_{T}} \frac{1}{2} m_{R j}\left(\frac{\partial z_{M}}{\partial t}\right)^{2}+\sum_{j=1}^{N_{T}} \frac{1}{2} m_{L j}\left(\frac{\partial z_{C}}{\partial t}\right)^{2} \\
& +\sum_{j=1}^{N_{T}} \frac{1}{2} m_{D j}^{\prime}\left(\frac{\partial z_{M}}{\partial t}-\frac{\partial z_{C}}{\partial t}\right)^{2},
\end{aligned}
$$

where $\rho_{M}^{\prime}, \rho_{C}^{\prime}, \rho_{A}^{\prime}$ are the density of messenger wire, contact wire, and auxiliary messenger wire after icing respectively; $S_{M}^{\prime}, S_{C}^{\prime}, S_{A}^{\prime}$ are the cross-sectional area of messenger wire, contact wire, and auxiliary messenger wire after icing respectively; $m_{R_{j}}$ and $m_{L_{j}}$ are the mass of $j$-th support rod and limiter, respectively; $m_{D j}{ }^{\prime}$ is the mass of $j$-th dropper after icing.

The expression of strain energy of OCS after icing is as follows:

$$
\begin{aligned}
V= & \frac{1}{2} \int_{0}^{L}\left(E_{M}^{\prime} I_{M}^{\prime}\left(\frac{\partial^{2} z_{M}}{\partial t^{2}}\right)^{2}+T_{M}\left(\frac{\partial z_{M}}{\partial t}\right)^{2}\right) \mathrm{d} t \\
& +\frac{1}{2} \int_{0}^{L}\left(E_{C}^{\prime} I_{C}^{\prime}\left(\frac{\partial^{2} z_{C}}{\partial t^{2}}\right)^{2}+T_{C}\left(\frac{\partial z_{C}}{\partial t}\right)^{2}\right) \mathrm{d} t \\
& +\frac{1}{2} \int_{0}^{l}\left(E_{A}^{\prime} I_{A}^{\prime}\left(\frac{\partial^{2} z_{A}}{\partial t^{2}}\right)^{2}+T_{A}\left(\frac{\partial z_{A}}{\partial t}\right)^{2}\right) \mathrm{d} t \\
& +\frac{1}{2} \sum_{j=1}^{N_{T}} k_{R j} z_{M}^{2}+\frac{1}{2} \sum_{j=1}^{N_{T}} k_{L j} z_{C}^{2}+\frac{1}{2} \sum_{j=1}^{N_{D}} k_{D j}\left(z_{M}-z_{C}\right)^{2},
\end{aligned}
$$

where $E_{M}^{\prime}, E_{C}^{\prime}, E_{A}^{\prime}$ are the elastic modulus of messenger wire, contact wire, and auxiliary messenger wire after icing, respectively; $I_{M}^{\prime}, I_{C}^{\prime}, I_{A}^{\prime}$ are the moment of inertia of messenger wire, contact wire, and auxiliary messenger wire after icing, respectively; $T_{M}^{\prime}, T_{C}^{\prime}, T_{A}^{\prime}$ are the tension of messenger wire, contact wire, and auxiliary messenger wire, respectively; $k_{R_{j}}$, $k_{L_{j}}, k_{D_{j}}$ are the stiffness of $j$-th support rod, limiter, respectively. 


\section{Numerical Results and Discussion}

In this section, some results of three different simulation models of icing are presented to analyze the influence of icing on the current collection quality of PAC system. In these scenarios, the pantograph moves along the catenary at a speed of $150 \mathrm{~km} / \mathrm{h}$ to $400 \mathrm{~km} / \mathrm{h}$. The ratio of catenary icing thickness to the cable radius is 0 to 3 . Only the contact force, vertical acceleration and vertical displacement that generated in the catenary between 150 and $300 \mathrm{~m}$ are analyzed.

4.1. Numerical Results of Increased Density Method. The vertical vibration characteristics of the pantograph passing through the ice-coated catenary at different positions (support positioning position, the first dropper, and the mid-span) are shown in Figure 6, with a different ratio of catenary icing thickness to cable radius by using the increased density method. The volume of the ice layer wrapped on the surface of the cable is ignored, and the mass caused by the ice layer is added to the cable, which means that the density of the cable is increased. It can be seen from the figure that the initial position of each point drops slightly, because the icing increases the mass of the catenary and the catenary sags under the action of gravity. Due to inertia, the vibration characteristics of key points on the contact wire also changed slightly. Specifically, as the ice thickness of the catenary increases, the vibration amplitude of each point decreases slightly, and the time required for each point to reach the highest point increases.

Table 4 shows the vertical uplift of the different positions (support positioning position, the first dropper, and the midspan) and their change rate when the pantograph runs along the catenary system with different ice thickness by using the increased density method. The results show that with the increase of ice thickness, the change trend of vertical uplift at different positions is different. When the pantograph passes through the support positioning, with the increase of ice thickness, the vertical uplift at the support positioning point increases continuously, the vertical uplift at the first dropper increases first and then decreases, and the vertical uplift at the midspan position decreases continuously. But in general, the effect of icing on the vertical uplift of each point on the contact wire is not obvious. When the ratio of ice thickness to cable radius reaches 3 , the change rate of the uplift of each point is not more than $0.25 \%$.

Figure 7 depicts the characteristics of the contact force and vertical acceleration that develop between the pantograph and catenary by using the increased density method. It can be observed that both the contact force and the vibration acceleration of the collector piece increase with increasing ice thickness. When the ratio of catenary icing thickness to cable radius increases from 0 to 3, the maximum acceleration of collector piece increases from $14.46 \mathrm{~m} / \mathrm{s}^{2}$ to $22.29 \mathrm{~m} / \mathrm{s}^{2}$, which increases by $54.15 \%$. The maximum contact force between pantograph and catenary increases from $312.17 \mathrm{~N}$ to $372.57 \mathrm{~N}$, which increases by $19.35 \%$. Ice is equivalent to a cable of the same mass, which increases the inertia of the cable. The change of the inertia of the catenary system increases with the increase of ice thickness, which causes the contact force and vertical acceleration to change greatly with the increase of ice thickness.

4.2. Numerical Results of Uniform Load Method. The uniform load method is used to calculate the vertical vibration characteristics of the pantograph passing through the ice covered catenary at different positions (support positioning position, the first dropper, and the mid-span) when the ratio of catenary icing thickness to cable radius is different, the results are shown in Figure 8. The ice layer wrapped on the surface of the cable is converted into the corresponding load. With the increase of icing thickness, the initial positions of each point slightly decreased under the effect of vertical distributed load. The vibration characteristics of key points on the contact wire also slightly change with the application of uniform load. The vibration amplitude of each point and the time required to reach the highest point decrease with the increase of the ice thickness of the catenary.

The vertical uplift of the different positions (support positioning position, the first dropper, and the midspan) and their change rate when the pantograph runs along the catenary system with different ice thicknesses by using the uniform load method are presented in Table 5. The results show that with the increase of ice thickness, the vertical uplift of each point of pantograph passing through the catenary decreases. The effect of icing on the vertical vibration of the contact wire at the first dropper is greater than that at the support positioning point and mid-span. When the ratio of ice thickness to cable radius reaches 3 , the change rate of the uplift at the first dropper is reduced by $3.48 \%$.

Figure 9 depicts the characteristics of the contact force and vertical acceleration that develop between the pantograph and catenary by using the uniform load method. It can be observed that both the contact force and the vibration acceleration of the collector piece increase with increasing ice thickness. When the ratio of catenary icing thickness to cable radius increases from 0 to 3 , the maximum acceleration of collector piece increases from $14.46 \mathrm{~m} / \mathrm{s}^{2}$ to $19.80 \mathrm{~m} / \mathrm{s}^{2}$, which increases by $39.00 \%$. The maximum contact force between pantograph and catenary increases from $312.17 \mathrm{~N}$ to $343.86 \mathrm{~N}$, which increases by $10.15 \%$. The dependency of the numerical result on the uniform load method can be explained considering that the contact force and vertical acceleration are influenced by the vertical uniform load.

4.3. Numerical Results of Combinatorial Material Method. The combinatorial material method is used to calculate the vertical vibration characteristics of the pantograph passing through the ice covered catenary at different positions (support positioning position, the first dropper, and the mid-span) when the ratio of catenary icing thickness to cable radius is different, the results are shown in Figure 10. The ice layer wrapped on the surface of the cable not only caused an increase in the mass of the cable per unit length, but also changed the cross-sectional area of the cable. Figure 10 shows that under the effect of gravity, the initial position of each point and the vertical uplift of each point decrease 


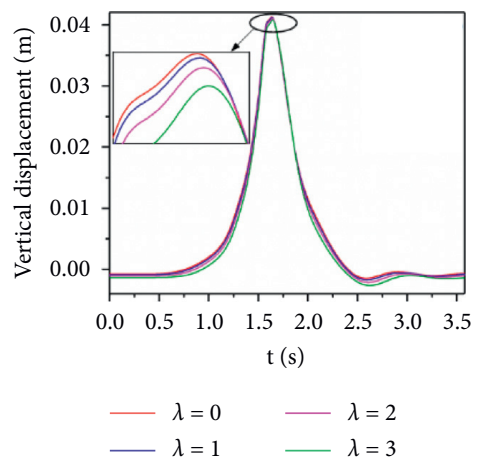

(a)

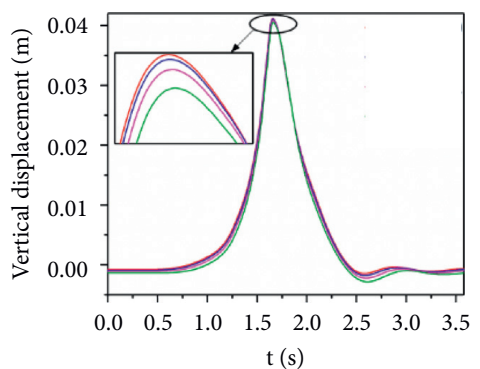

$-\lambda=0 \quad-\lambda=2$

(b)

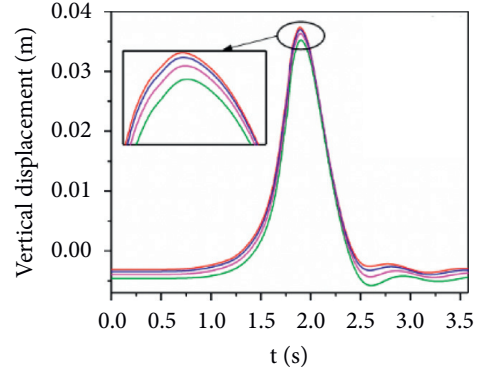

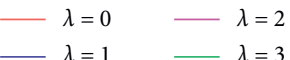

(c)

FiguRE 6: Characteristic curve of specific point (increased density method). (a) Support positioning position. (b) The first dropper. (c) The mid-span.

TABle 4: Statistical value of vertical uplift at different positions after icing (increased density method).

\begin{tabular}{lcccccc}
\hline \multirow{2}{*}{ Icing thickness } & \multicolumn{2}{c}{ Support positioning position } & \multicolumn{2}{c}{ The first dropper } & \multicolumn{2}{c}{ The mid-span } \\
& Uplift $(\mathrm{m})$ & Rate $(\%)$ & Uplift $(\mathrm{m})$ & Rate $(\%)$ & Uplift $(\mathrm{m})$ & Rate $(\%)$ \\
\hline$\lambda=0$ & 0.04203 & - & 0.04193 & - & 0.04047 & - \\
$\lambda=1$ & 0.04208 & 0.10 & 0.04195 & 0.04 & 0.04039 & -0.19 \\
$\lambda=2$ & 0.04212 & 0.20 & 0.04194 & 0.02 & 0.0402 & -0.66 \\
$\lambda=3$ & 0.04213 & 0.24 & 0.04187 & -0.16 & 0.03984 & -1.57 \\
\hline
\end{tabular}

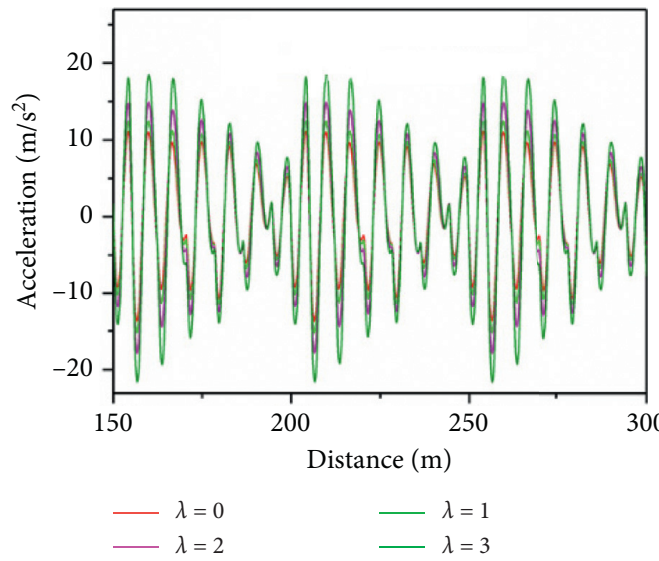

(a)
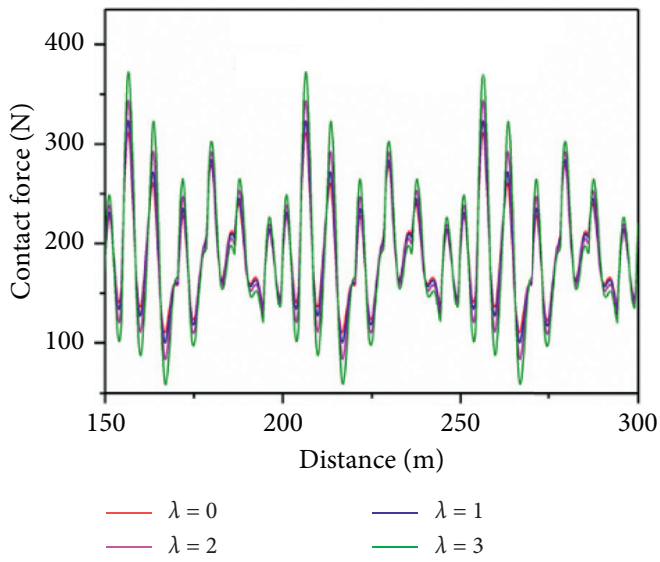

(b)

FIgURE 7: Dynamic characteristics between pantograph and catenary (increased density method). (a) Acceleration. (b) Contact force.

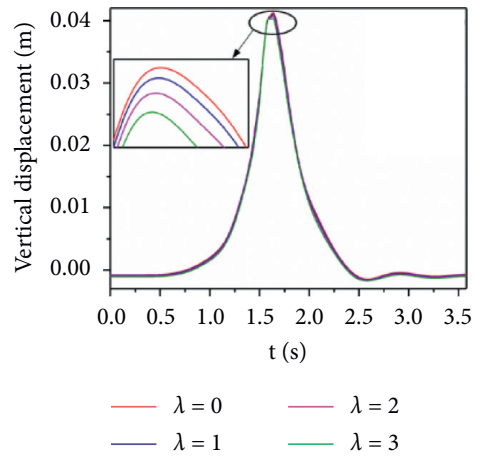

(a)
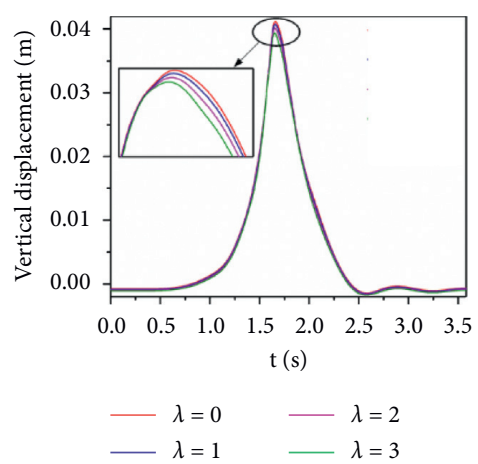

(b)

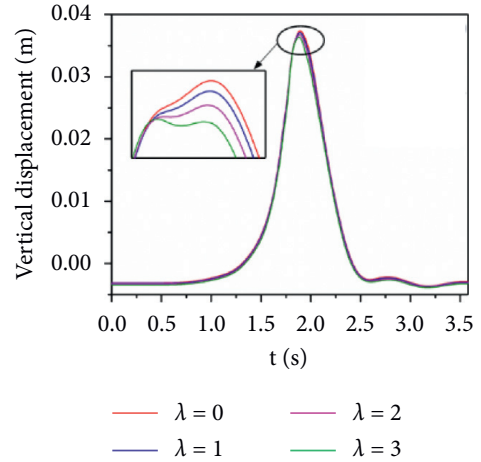

(c)

FIGURE 8: Characteristic curve of specific point (uniform load method). (a) Support positioning position. (b) The first dropper. (c) The midspan. 
TABLE 5: Statistical value of uplift at different positions after icing (uniform load method).

\begin{tabular}{lccccc}
\hline \multirow{2}{*}{ Icing thickness } & \multicolumn{2}{c}{ Support positioning position } & \multicolumn{2}{c}{ The first dropper } & \multicolumn{2}{c}{ The midspan } \\
& Uplift $(\mathrm{m})$ & Rate $(\%)$ & Uplift $(\mathrm{m})$ & Rate $(\%)$ & Uplift $(\mathrm{m})$ \\
\hline$\lambda=0$ & 0.04203 & - & 0.04193 & - & 0.04047 \\
$\lambda=1$ & 0.04189 & -0.33 & 0.04162 & -0.74 & 0.04031 \\
$\lambda=2$ & 0.04168 & -0.85 & 0.04113 & -1.92 & 0.04007 \\
$\lambda=3$ & 0.04146 & -1.37 & 0.04047 & -3.48 & 0.03978 \\
\hline
\end{tabular}

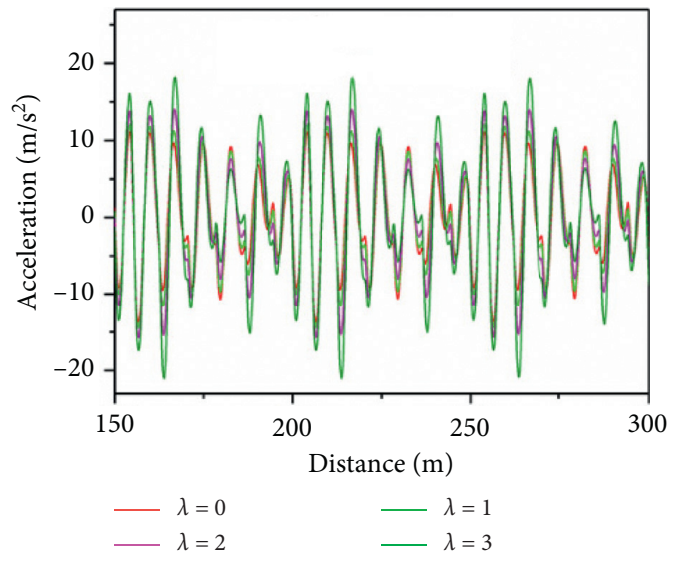

(a)

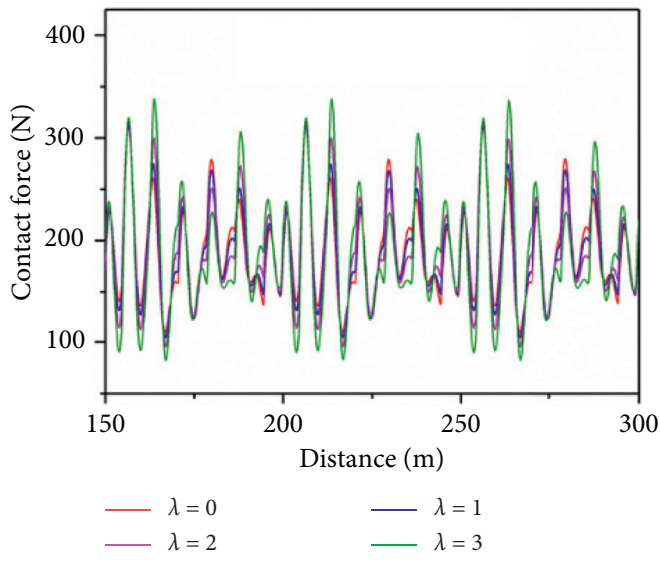

(b)

Figure 9: Dynamic characteristics between pantograph and catenary (Uniform Load Method). (a) Acceleration. (b) Contact force.

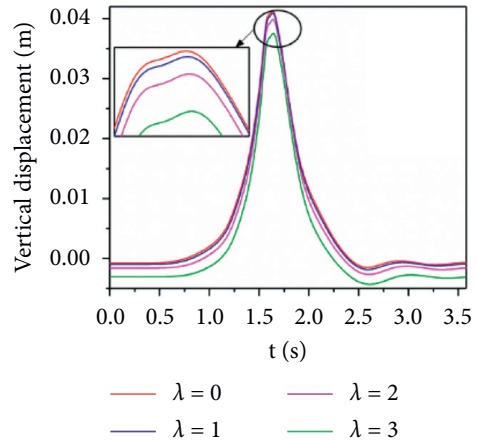

(a)

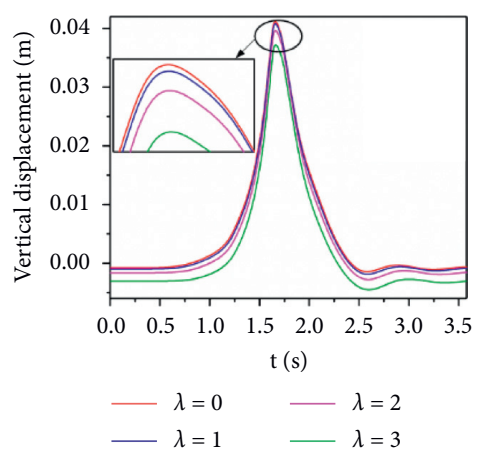

(b)

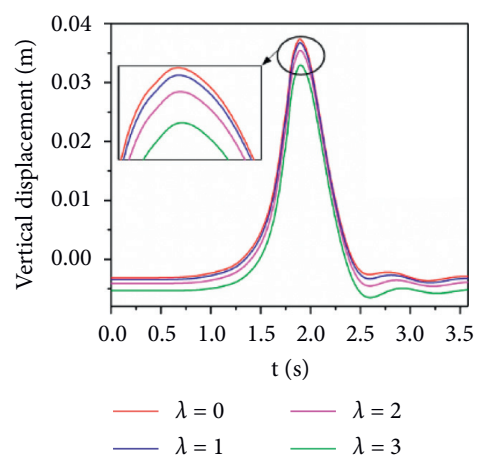

(c)

FIgURE 10: Characteristic curve of specific point (combinatorial material method). (a) Support positioning position. (b) The first dropper. (c) The mid-span.

with increasing ice thickness. With the increase of ice thickness, the vibration characteristics of key points on the catenary also changed. As the ice thickness of the catenary increases, the vibration amplitude of each point decreases slightly, and the time required for each point to reach the highest point increases.

The vertical uplift of the different positions (support positioning position, the first dropper, and the midspan) and their change rate when the pantograph runs along the catenary system with different ice thickness by using the combinatorial material method are presented in Table 6 . The results show that with the increase of ice thickness, the vertical uplift of each point of pantograph passing through the catenary decreases. The effect of icing on the vertical vibration of the contact wire at the midspan is greater than that at the support positioning point and first dropper. When the ratio of ice thickness to cable radius reaches 3 , the change rate of the uplift at the first dropper decreases to $5.46 \%$.

Figure 11 depicts the characteristics of the contact force and vertical acceleration that develop between the pantograph and catenary by using the combinatorial material method. Both the contact force and the vibration acceleration of the collector piece increase with increasing ice 
TABLE 6: Statistical value of uplift at different positions after icing (combinatorial material method).

\begin{tabular}{lccccc}
\hline \multirow{2}{*}{ Icing thickness } & \multicolumn{2}{c}{ Support positioning position } & \multicolumn{2}{c}{ The first dropper } & \multicolumn{2}{c}{ The midspan } \\
& Uplift $(\mathrm{m})$ & Rate $(\%)$ & Uplift $(\mathrm{m})$ & Rate $(\%)$ & Uplift $(\mathrm{m})$ \\
\hline$\lambda=0$ & 0.04203 & - & 0.04193 & - & 0.04047 \\
$\lambda=1$ & 0.04188 & -0.35 & 0.04176 & -0.43 & 0.04019 \\
$\lambda=2$ & 0.04146 & -1.37 & 0.04125 & -1.62 & 0.03952 \\
$\lambda=3$ & 0.04059 & -3.42 & 0.04026 & -4.00 & 0.03826 \\
\hline
\end{tabular}

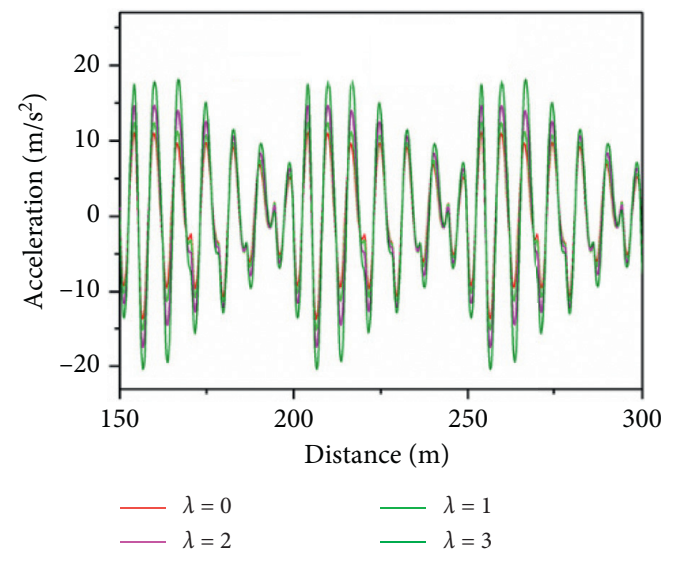

(a)

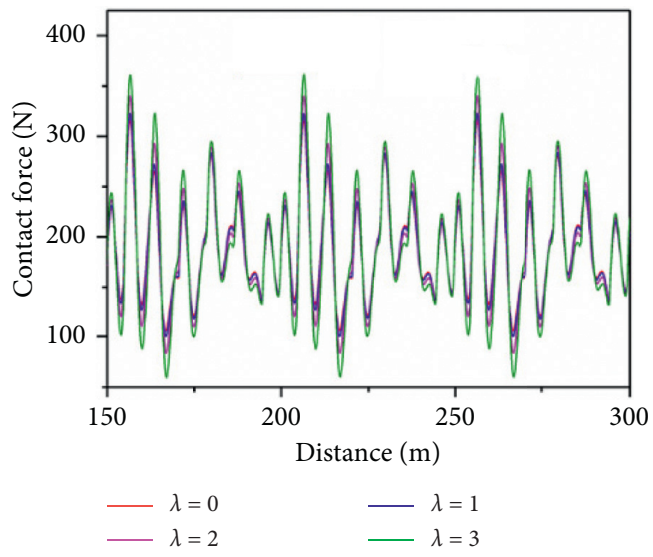

(b)

FIGURE 11: Dynamic characteristics between pantograph and catenary (combinatorial material method). (a) Acceleration. (b) Contact force.

thickness. When the ratio of catenary icing thickness to cable radius increases from 0 to 3 , the maximum acceleration of collector piece increases from $14.46 \mathrm{~m} / \mathrm{s}^{2}$ to $21.85 \mathrm{~m} / \mathrm{s}^{2}$, which increases by $51.11 \%$. The maximum contact force between pantograph and catenary increases from $312.17 \mathrm{~N}$ to $343.86 \mathrm{~N}$, which increases by $15.86 \%$. The dependency of the numerical result on the combinatorial material method can be explained considering that the contact force and vertical acceleration and vertical displacement are influenced by the inertia and property of cable-ice coupling material after icing.

4.4. Discussion of Three Different Methods of Icing. A further computation analysis is carried out to study the dynamic characteristics of the pantograph-catenary system with the increase of ice thickness when the pantograph runs at different speeds. In all scenarios shown in Figures 12-14, the pantograph moves along the catenary at the speed of $150 \mathrm{~km} / \mathrm{h}$ to $400 \mathrm{~km} / \mathrm{h}$ and the ratio of catenary icing thickness to cable radius is 0 to 3 . The contact force and vertical acceleration develop in the catenary between $150 \mathrm{~m}$ and $300 \mathrm{~m}$ are extracted and analyzed.

Figure 12 depicts the maximum acceleration and the statistical minimum of contact force when the pantograph passes through the catenary system with different icing thicknesses at different speeds by using the increased density method.

As shown in Figure 12(a) that when the running speed is constant, the vibration of the collector head becomes severe with the increase of ice thickness. When the train is running at $150 \mathrm{~km} / \mathrm{h}$, the impact of ice thickness on vibration acceleration of collector head is relatively small, and the acceleration amplitude is increased by $57.69 \%$ with the ratio of catenary icing thickness to cable radius increases to 3 . When the train is running at $400 \mathrm{~km} / \mathrm{h}$, the impact of ice thickness on vibration acceleration of collector head is obvious, and the acceleration amplitude is increased by $66.92 \%$ with the ratio of catenary icing thickness to cable radius increases to 3.

It can be seen from Figure 12(b) that when the running speed is constant, the statistical minimum of the contact force between the pantograph and catenary decreases as the thickness of the ice coating increases. The influence of ice thickness on current collection becomes obvious with the increase of the operating speed. When the pantograph runs at a speed of $150 \mathrm{~km} / \mathrm{h}$ and the ratio of catenary icing thickness to cable radius reaches 3 , the statistical minimum of the contact force decreases from $41.86 \mathrm{~N}$ to $10.75 \mathrm{~N}$. At this time, good current collection quality can still be guaranteed. When the pantograph runs at a speed of $400 \mathrm{~km} /$ $\mathrm{h}$ and the ratio of catenary icing thickness to cable radius reaches 3 , the statistical minimum of the contact force decreases from $37.61 \mathrm{~N}$ to $-82.18 \mathrm{~N}$. At this time, the current collection quality cannot be guaranteed.

Figure 13 depicts the maximum acceleration and the statistical minimum of contact force when the pantograph passes through the catenary system with different icing thickness at different speeds by using the uniform load method. 


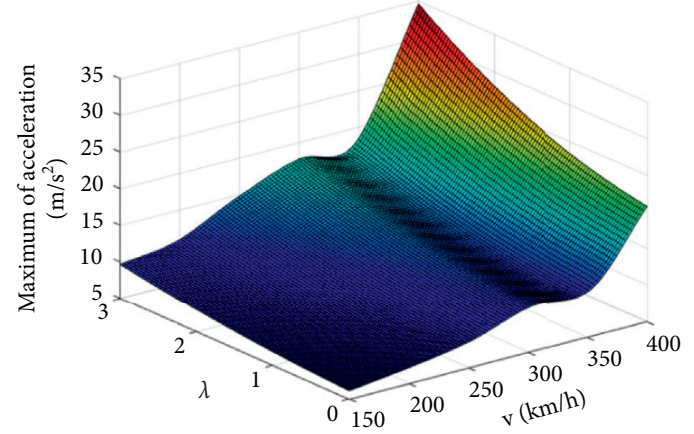

(a)

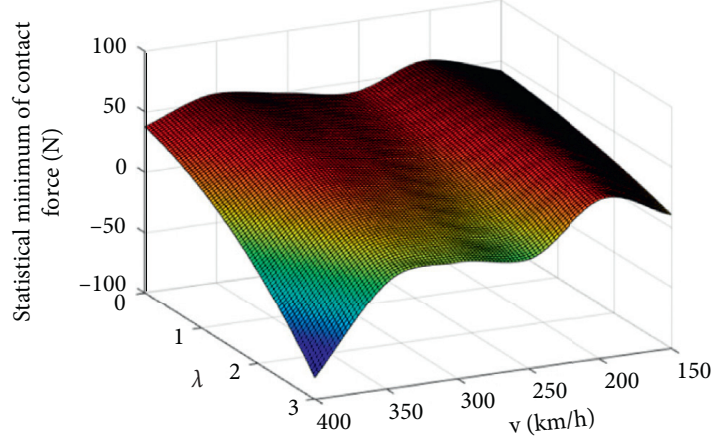

(b)

FIGURE 12: The influence of ice thickness on the current collection quality under different operating speeds (increased density method). (a). Maximum of acceleration; (b) statistical minimum of contact force.

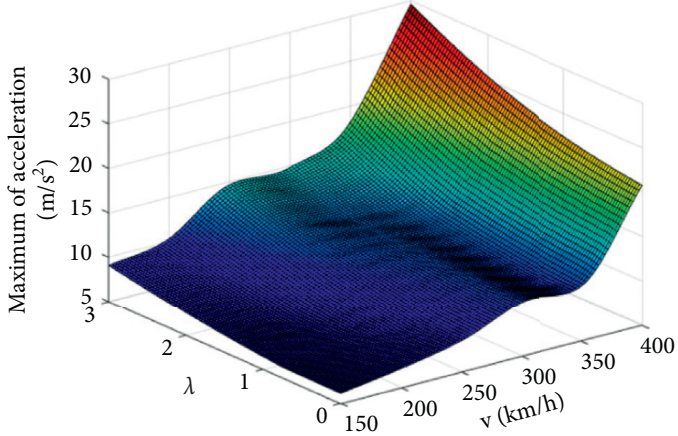

(a)

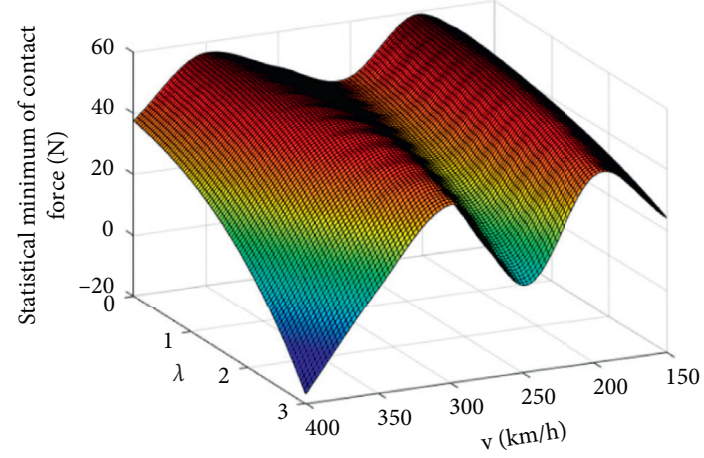

(b)

FIGURE 13: The influence of ice thickness on the current collection quality under different operating speeds (Uniform Load Method). (a). Maximum of acceleration, (b) statistical minimum of contact force.

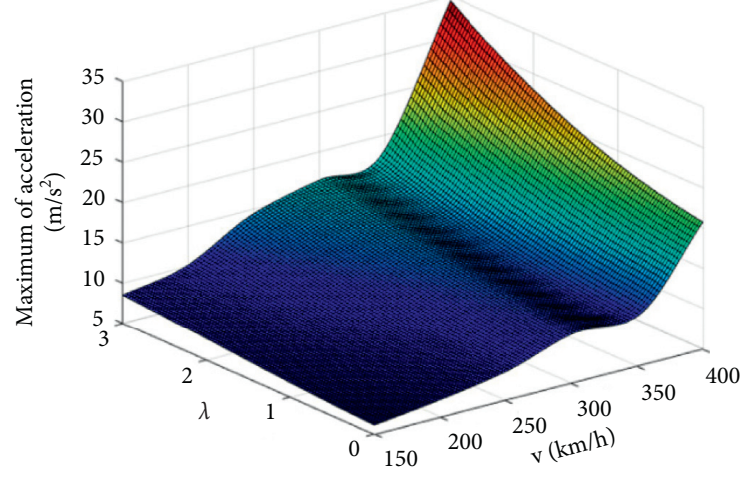

(a)

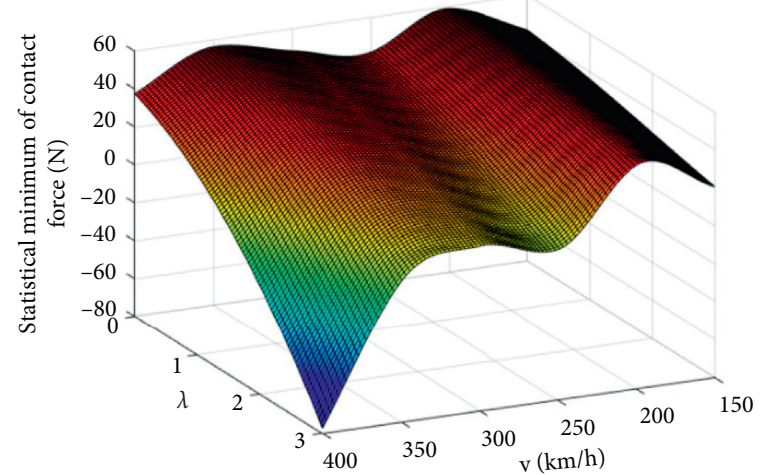

(b)

Figure 14: The influence of ice thickness on the current collection quality under different operating speeds (combinatorial material method). (a). Maximum of acceleration; (b) statistical minimum of contact force.

As shown in Figure 13(a) that when the running speed is constant, the vibration of the collector head becomes severe with the increase of ice thickness. When the train is running at $150 \mathrm{~km} / \mathrm{h}$, the impact of ice thickness on vibration acceleration of collector head is relatively small, and the acceleration amplitude is increased by $48.50 \%$ with the ratio of catenary icing thickness to cable radius increasing to 3 . When the train is running at $400 \mathrm{~km} / \mathrm{h}$, the impact of ice thickness on vibration acceleration of collector head is obvious, and the acceleration amplitude is increased by 

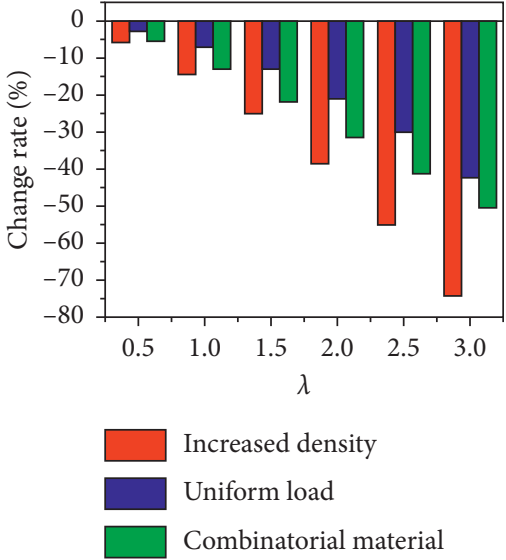

(a)

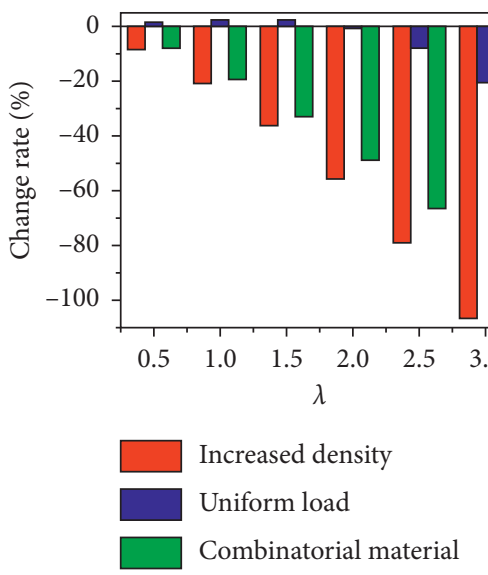

(d)

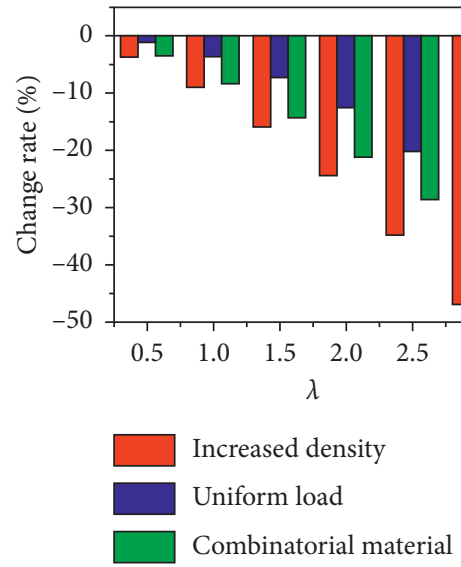

(b)
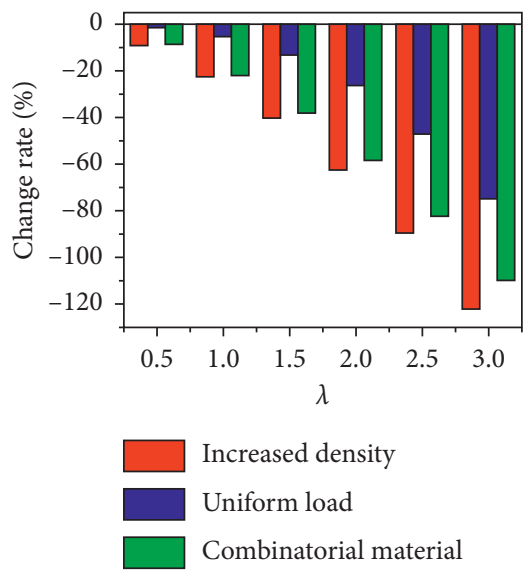

(e)

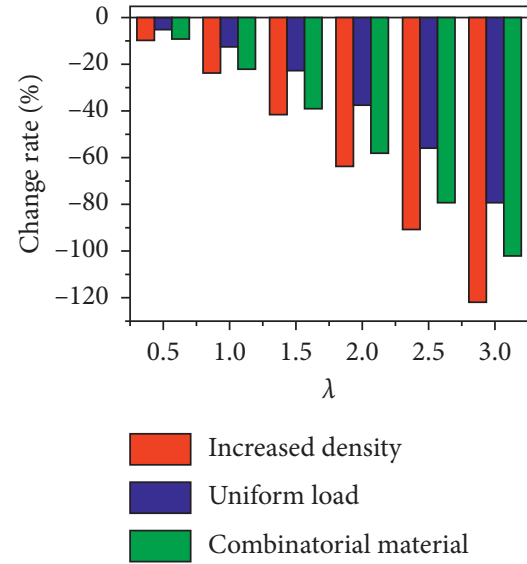

(c)
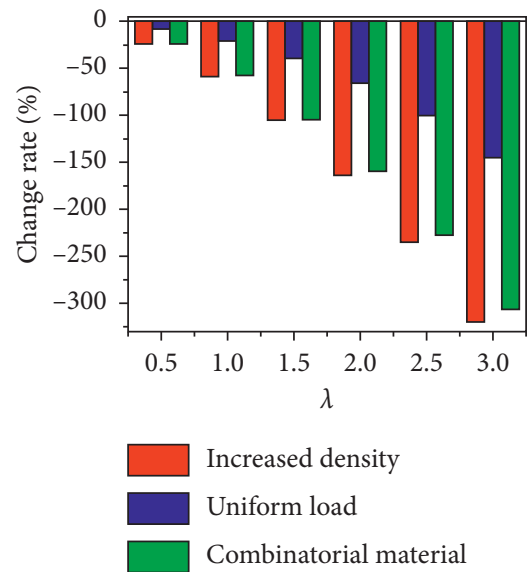

(f)

FIGURE 15: Comparison of statistical minimum of contact force calculated by three different methods: (a) $v=150 \mathrm{~km} / \mathrm{h}$; (b) $v=200 \mathrm{~km} / \mathrm{h}$; (c) $v=250 \mathrm{~km} / \mathrm{h} ;(\mathrm{d}) v=300 \mathrm{~km} / \mathrm{h} ;(\mathrm{e}) v=350 \mathrm{~km} / \mathrm{h} ;(\mathrm{f}) . v=400 \mathrm{~km} / \mathrm{h}$.

$42.90 \%$ with the ratio of catenary icing thickness to cable radius increases to 3 .

It can be seen from Figure 13(b) that when the running speed is constant, the statistical minimum of the contact force between the pantograph and catenary decreases as the thickness of the ice coating increases. The influence of ice thickness on the current collection becomes obvious with the increase of the operating speed. When the pantograph runs at a speed of $150 \mathrm{~km} / \mathrm{h}$ and the ratio of catenary icing thickness to cable radius reaches 3 , the statistical minimum of the contact force decreases from $41.86 \mathrm{~N}$ to $24.16 \mathrm{~N}$. At this time, good current collection quality can still be guaranteed. When the pantograph runs at a speed of $400 \mathrm{~km} /$ $\mathrm{h}$ and the ratio of catenary icing thickness to cable radius reaches 3 , the statistical minimum of the contact force decreases from $37.61 \mathrm{~N}$ to $-16.91 \mathrm{~N}$. At this time, the current collection quality cannot be guaranteed.

Figure 14 depicts the maximum acceleration and the statistical minimum of contact force when the pantograph passes through the catenary system with different icing thickness at different speeds by using the combinatorial material method.
As shown in Figure 14(a) that when the running speed is constant, the vibration of the collector head becomes severe with the increase of ice thickness. When the train is running at $150 \mathrm{~km} / \mathrm{h}$, the impact of ice thickness on vibration acceleration of collector head is relatively small, and the acceleration amplitude is increased by $38.83 \%$ with the ratio of catenary icing thickness to cable radius increases to 3 . When the train is running at $400 \mathrm{~km} / \mathrm{h}$, the impact of ice thickness on vibration acceleration of collector head is obvious, and the acceleration amplitude is increased by $65.99 \%$ with the ratio of catenary icing thickness to cable radius increasing to 3.

It can be seen from Figure 14(b) that when the running speed is constant, the statistical minimum of the contact force between the pantograph and catenary decreases as the thickness of the ice coating increases. The influence of ice thickness on the current collection becomes obvious with the increase of the operating speed. When the pantograph runs at a speed of $150 \mathrm{~km} / \mathrm{h}$ and the ratio of catenary icing thickness to cable radius reaches 3 , the statistical minimum of the contact force decreases from $41.86 \mathrm{~N}$ to $20.77 \mathrm{~N}$. At this time, good current collection quality can still be 
guaranteed. When the pantograph runs at a speed of $400 \mathrm{~km} /$ $\mathrm{h}$ and the ratio of catenary icing thickness to cable radius reaches 3 , the statistical minimum of the contact force decreases from $37.61 \mathrm{~N}$ to $-77.33 \mathrm{~N}$. At this time, the current collection quality cannot be guaranteed.

Figure 15 shows the change rate of the statistical minimum of contact force calculated by three different methods with the increase of ice thickness when the train runs at different speeds. It can be seen from the figure that the icing of the catenary system at different operating speeds results in the current collection quality of the pantograph catenary system to different degrees. The trend of the statistical minimum of contact force calculated by the three different methods is basically consistent with the variation of ice thickness. However, the values of the calculation results are different.

When the ice is thinner, the statistical minimum of contact force calculated by the three methods are close. However, with the increase of ice thickness, the difference of the statistical minimum of contact force calculated by the three methods gradually becomes obvious. In addition, the influence of icing thickness on the current collection quality of pantograph catenary system is different under different operating speeds. Specifically, when the running speed is less than $200 \mathrm{~km} / \mathrm{h}$ and the ratio of ice thickness to cable radius reaches 3 , the reduction rate of the statistical minimum of contact force is not more than $100 \%$. When the running speed exceeds $200 \mathrm{~km} / \mathrm{h}$ and the ratio of ice thickness to cable radius reaches 3 , the reduction rate of the statistical minimum of contact force is more than $100 \%$. It means that the current collection quality decreases sharply with the increase of ice thickness.

It can be seen that the results calculated by the uniform load method are small and the error is the largest. The results of increased density method and combinatorial material method are relatively close. However, the increased density method only considers the change of the inertia caused by the ice, and the combinatorial material method considers not only the inertial characteristics caused by the ice but also the change in the shape of the cable. Therefore, the calculation results of the combined material method are more reasonable.

\section{Conclusions}

A dynamic model of pantograph and catenary considering icing is proposed in this paper. The finite element method is used to build the catenary and the pantograph is built as a lumped-mass model. Three different methods are put forward to solve the ice covering of catenary system, which are increased density method, uniform load method, and combinatorial material method. In this model, the key parts such as messenger wire, contact wire, auxiliary messenger wire, and dropper are all considered to be covered with ice.

The similarities and differences between the three simulation methods are compared. The results of the three methods show that the icing of the catenary system will lead to the poor current collection quality of the PAC system. And the current collection quality of the PAC system will deteriorate rapidly with the increase of the ice thickness. When the ice coating is processed into three different forms, the results of the three methods have some differences. The influence of the ice thickness on the current collection quality between the pantograph and catenary at the different operating speeds calculated by the three methods is basically the same, which fully illustrates the effectiveness of the simulated ice coating method. However, from the numerical value of the calculation results, the influence of icing calculated by the uniform load method on the pantograph catenary current collection quality is small. The results obtained by the increased density method and combinatorial material method are relatively close. The combinatorial material method is more reasonable because it takes into account not only the change in the inertia of the catenary system caused by icing, but also the change in the shape of the cable.

The research also shows that the influence of icing on the current collection quality of pantograph catenary is different when the train runs at different speeds. Specifically, when the train runs at a higher speed, the current collection quality of PAC system is more easily affected by the icing of catenary system. The higher the train speed and the thicker the ice layer covering the surface of catenary, the worse the current collection quality of the pantograph catenary system.

\section{Data Availability}

The data supporting the results can be obtained through e-mail,yaoyongming@my.swjtu.edu.cn.

\section{Conflicts of Interest}

The authors declare that there are no conflicts of interest regarding the publication of this paper.

\section{Acknowledgments}

This project was supported by the National Natural Science Foundation of China (No.51475391), National Key Research and Development Program of China (No.2017YFB1201201), the China Railway Corporation Technology Research and Development Program (No.2017J008-L), the Fundamental Research Funds for the Central Universities (No.2682018CX71), and Chinese Scholarship Council (CSC) Foundation which are highly appreciated by the authors.

\section{References}

[1] Z. Xu, Y. Song, and Z. Liu, "Effective measures to improve current collection quality for double pantographs and catenary based on wave propagation analysis," IEEE Transactions on Vehicular Technology, vol. 69, no. 6, pp. 6299-6309, 2020.

[2] V. I. Hudym, A. S. Jagiełło, J. Prusak et al., "Preventing the formation of ice on the catenary lines," Czasopismo Techniczne, vol. 2016, pp. 173-183, 2016.

[3] J. Ambrósio, J. Pombo, M. Pereira, P. Antunes, and A. Mósca, "Recent developments in pantograph-catenary interaction modelling and analysis," International Journal of Railway Technology, vol. 1, no. 1, pp. 249-278, 2012. 
[4] J. Hou, Y. Li, and Z. Sun, "Unbalanced tensions and vertical space calculation of tranmission lines under non-uniform icecoating and ice-shedding," Energy Procedia, vol. 17, pp. 1034-1042, 2012.

[5] W. Zhang, G. Mei, and J. Zeng, "A study of pantograph/ catenary system dynamics with influence of presag and irregularity of contact wire," Vehicle System Dynamics, vol. 37, no. sup1, pp. 593-604, 2002.

[6] Y. Song, Z. Liu, A. Rxnnquist, P. Navik, and Z. Liu, "Contact wire irregularity stochastics and effect on high-speed railway pantograph-catenary interactions," IEEE Transactions on Instrumentation and Measurement, p. 1, 2020.

[7] A. Collina, F. Fossati, M. Papi, and F. Resta, "Impact of overhead line irregularity on current collection and diagnostics based on the measurement of pantograph dynamics," Proceedings of the Institution of Mechanical Engineers, Part F: Journal of Rail and Rapid Transit, vol. 221, no. 4, pp. 547-559, 2007.

[8] S. Bruni, J. Ambrosio, A. Carnicero et al., "The results of the pantograph-catenary interaction benchmark," Vehicle System Dynamics, vol. 53, no. 3, pp. 412-435, 2015.

[9] J. Pombo and J. Ambrósio, "Influence of pantograph suspension characteristics on the contact quality with the catenary for high speed trains," Computers \& Structures, vol. 110111, pp. 32-42, 2012.

[10] S. Bruni, G. Bucca, M. Carnevale, A. Collina, and A. Facchinetti, "Pantograph-catenary interaction: Recent achievements and future research challenges," International Journal of Rail Transportation, vol. 6, no. 2, pp. 57-82, 2018.

[11] P. Nåvik, A. Rønnquist, and S. Stichel, "Variation in predicting pantograph-catenary interaction contact forces, numerical simulations and field measurements," Vehicle System Dynamics, vol. 55, no. 9, pp. 1265-1282, 2017.

[12] M. Zhao, D. Jiang, and S. Li, "Research on fault mechanism of icing of wind turbine blades," in Proceedings of the World Non-Grid-Connected Wind Power and Energy Conference, pp. 1-4, Nanjing, China, September 2009.

[13] L. Makkonen, "Modeling of ice accretion on wires," Journal of Climate and Applied Meteorology, vol. 23, no. 6, pp. 929-939, 1984.

[14] Li Zhao, Bo Yan, C. A. I. Meng-qi et al., "Numerical simulation for galloping of iced conductors in a transmission tower-line system," Journal of Vibration \& Shock, vol. 32, pp. 113-120, 2013.

[15] F. Duan, Z. Liu, Y. Song, and J. Zhang, "Influences of ice load and air damping on dynamic current collection of pantograph-iced catenary," Journal of Southwest Jiaotong University, vol. 1, p. 25, 2016.

[16] B. E. Kringlebotn Nygaard, H. Ágústsson, and K. SomfalviTóth, "Modeling wet snow accretion on power lines: Improvements to previous methods using 50 Years of observations," Journal of Applied Meteorology and Climatology, vol. 52, no. 10, pp. 2189-2203, 2013.

[17] R. A. Da Silveira, C. R. Maliska, D. A. Estivam et al., "Evaluation of Collection Efficiency Methods for Icing analysis," in Proceedings of the 17th International Congress of Mechanical Engineering, São Paulo, Brazil, 2003.

[18] P. Fu, M. Farzaneh, and G. Bouchard, "Two-dimensional modelling of the ice accretion process on transmission line wires and conductors," Cold Regions Science and Technology, vol. 46, no. 2, pp. 132-146, 2006.

[19] P. Fu and M. Farzaneh, "Simulation of the ice accretion process on a transmission line cable with differential twisting," Canadian Journal of Civil Engineering, vol. 34, no. 2, pp. 147-155, 2007.

[20] G. F. Naterer, "Coupled liquid film and solidified layer growth with impinging supercooled droplets and Joule heating," International Journal of Heat and Fluid Flow, vol. 24, no. 2, pp. 223-235, 2003.

[21] R. W. Lenhard, "An indirect method for estimating the weight of glaze on wires," Bulletin of the American Meteorological Society, vol. 36, no. 1, pp. 1-5, 1955.

[22] P. M. Chaine and P. Skeates, Ice Accretion Handbook (Freezing Precipitation), Industrial Meteorology - Study VI, Environmental Canada, Toronto, Canada, 1974.

[23] T. C. Yip and P. Mitten, Comparisons between Different Ice Accretion Models, Canadian Electrical Association, Montreal, Canada, 1991.

[24] I. Imai, "Studies on ice accretion," Researches on Snow and Ice, vol. 3, no. 1, pp. 35-44, 1953.

[25] L. Makkonen and J. R. Stallabrass, "Ice accretion on cylinder and wires," Tech. Rep. TRLT-005, National Research Council Canada, Ottawa, Canada, 1984.

[26] E. J. Goodwin, J. Mozer, and B. Power, Predicting Ice and Snow Loads for Transmission Line Design, Penna Power \& Light Co, Allentown, Pennsylvania, 1983.

[27] P. M. Chaîné and G. Castonguay, New Approach to Radial Ice Thickness Concept Applied to Bundle-Like Conductors, Environment Canada, Atmospheric Environment, Ottawa, Canada, 1974.

[28] H. Liu, D. Zhou, J. Fu, and S. Huang, "A simple model for predicting glaze loads on wires," in Proceedings of the CSEE, vol. 21, no. 4, pp. 44-47, Luleå, Sweden, May 2001.

[29] P. McComber and J. W. Govoni, "An analysis of selected ice accretion measurements on a wire at Mount Washington," in Proceedings of the Forty-Second Annual Eastern Snow Conference, Montreal, Canada, 1985.

[30] W. Tang, H. Liu, H. Li, and H. Guo, "Experimental study of icing of contact wires in icing wind tunnels," East China Electric Power, vol. 37, no. 2, pp. 250-252, 2009.

[31] Y. Zhu, X. Huang, J. Jia et al., "Numerical simulation for icing and influence on transmission line," Journal of Xi'an Jiaotong University, vol. 49, no. 7, pp. 120-125, 2015.

[32] X. Ma, J. Gao, C. Wu et al., "Prediction model for icing thickness of power transmission line based on grey support vector machine," Electric Power, vol. 49, no. 11, pp. 46-50, 2016.

[33] X. Jiang, F. Jiang, Q. Wang et al., "Prediction of rime accretion on transmission line based on optimal time step model," Transactions of China Electrotechnical Society, vol. 33, no. 18, pp. 4408-4418, 2018.

[34] J. Xu, W. Zheng, X. Huang et al., "Transmission line icing prediction model under micro-meteorological conditions," Electric Power, vol. 47, no. 2, pp. 58-63, 2014.

[35] M. T. Stickland and T. J. Scanlon, "An investigation into the aerodynamic characteristics of catenary contact wires in a cross-wind," Proceedings of the Institution of Mechanical Engineers, Part F: Journal of Rail and Rapid Transit, vol. 215, no. 4, pp. 311-318, 2001.

[36] G. Chen, Y. Yang, Y. Yang, and L. Peng, "Study on galloping oscillation of iced catenary system under cross winds," Shock and Vibration, vol. 2017, pp. 1-16, Article ID 1634292, 2017.

[37] Y. Song, Z. Liu, H. Wang, J. Zhang, X. Lu, and F. Duan, "Analysis of the galloping behaviour of an electrified railway overhead contact line using the non-linear finite element method," Proceedings of the Institution of Mechanical 
Engineers, Part F: Journal of Rail and Rapid Transit, vol. 232, no. 10, pp. 2339-2352, 2018.

[38] S. Avila-Sanchez, O. Lopez-Garcia, A. Cuerva, and J. Meseguer, "Assesment of the transverse galloping stability of a railway overhead located above a railway bridge," International Journal of Mechanical Sciences, vol. 131-132, pp. 649-662, 2017.

[39] T. J. Scanlon and A. B. Oldroyd, "An investigation into the attenuation of wind speed by the use of windbreaks in the vicinity of overhead wires," Proceedings of the Institution of Mechanical Engineers, Part F: Journal of Rail and Rapid Transit, vol. 214, no. 3, pp. 173-182, 2000.

[40] Z. Yan, Z. Li, E. Savory, and W. E. Lin, "Galloping of a single iced conductor based on curved-beam theory," Journal of Wind Engineering and Industrial Aerodynamics, vol. 123, pp. 77-87, 2013.

[41] Y. Song, Z. Liu, and H. Wang, "Study on aerodynamic parameters and wind vibration responses of iced contact wires of high-speed railways," Journal of the China Railway Society, vol. 36, no. 9, pp. 20-27, 2014.

[42] Y. Song, Z. Liu, H. Wang, X. Lu, and J. Zhang, "Nonlinear analysis of wind-induced vibration of high-speed railway catenary and its influence on pantograph-catenary interaction," Vehicle System Dynamics, vol. 54, no. 6, pp. 723-747, 2016.

[43] Q. Xie, W. Wang, H. Zhang et al., "Wind tunnel test on aerodynamic force characteristics of ice coating contact wire for high-speed railway," China Railway Science, vol. 35, no. 1, pp. 78-85, 2014.

[44] J. Xie, Y. Wang, Z. Liu et al., "Finite element simulation and small scale model experiment of catenary icing," in Proceedings of the CSEE, pp. 185-192, Hangzhou, China, 2013.

[45] M. Li, L. Guo, and J. Guan, "Finite element simulation of dynamic response of the catenary icing and de -icing," Journal of Railway Science and Engineering, vol. 12, no. 3, pp. 643-649, 2015.

[46] F. G. Rauter, J. Pombo, J. Ambrósio, J. Chalansonnet, A. Bobillot, and M. S. Pereira, "Contact model for the pantograph-catenary interaction," Journal of System Design and Dynamics, vol. 1, no. 3, pp. 447-457, 2007.

[47] W. Tianxing, "Analysis and calculation of catenary by FEM," Journal of the China Railway Society, vol. 18, no. 3, pp. 44-49, 1996.

[48] European Committee for Electrotechnical Standardization EN50318, Railway Applications- Current Collection SystemsValidation of Simulation of the Dynamic Interaction between Pantograph and Overhead Contact Line, CENELEC Central Secretariat, Brussels, Belgium, 2018. 